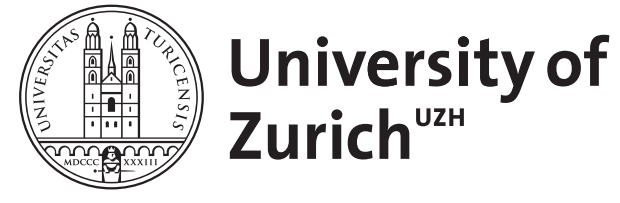

Zurich Open Repository and Archive

University of Zurich

University Library

Strickhofstrasse 39

CH-8057 Zurich

www.zora.uzh.ch

Year: 2013

\title{
Wir selbstbestimmte Menschen?
}

Neuner-Jehle, S

Posted at the Zurich Open Repository and Archive, University of Zurich ZORA URL: https://doi.org/10.5167/uzh-93670

Journal Article

Published Version

Originally published at:

Neuner-Jehle, S (2013). Wir selbstbestimmte Menschen? PrimaryCare, 13(16):302. 


\title{
Wir selbstbestimmte Menschen?
}

\author{
Aus der Reihe «kaffeetischphilosophische Mini-Essays»
}

Schon im Kindergarten lernen wir Ordnung und Gleichförmigkeit kennen: Die Finken haben in einer geraden Reihe zu stehen, so beschränkt sich das Suchen derselben auf ein vernünftiges Mass. Mein Primarlehrer, dessen Namen und Aussehen stark an Meister Lämpel aus den Werken von Wilhelm Busch erinnerte, setzte noch einen drauf: Nur wer sein Blatt äusserst exakt und korrekt ausfüllte, konnte vor ihm bestehen andernfalls setzte es auch mal eine Kopfnuss. So feilte ich an heissen, schönen Sommernachmittagen an meinen Hausaufgaben, bis sie perfekt waren. Gleichzeitig blutete mir aber das Herz, denn viel lieber hätte ich mit meinen Kollegen draussen Fussball gespielt. Ich lernte dadurch Wichtiges: Mit exaktem Arbeiten kommt man weiter (keine Kopfnüsse), leidet aber auch darunter (der Sommernachmittag drinnen am Schreibtisch). Ich lernte also, Prioritäten zu setzen (das Fussballspiel draussen war mir eben mindestens so wichtig wie das Ausbleiben von Kopfnüssen) und meine Kräfte ökonomisch und vorausschauend einzusetzen: Im «Arbeitsbuch Rechnen» achtete ich darauf, dass ich immer etwa 20 Seiten weiter war als die Klasse. So konnte ich meine freien Sommernachmittage wieder einziehen und hatte meine Aufgaben immer noch pflichtschuldig erledigt.

In der Sekundarstufe nahm die Diversität der Lehrpersonen zu.

Am besten erinnere ich mich an unseren Klassenlehrer, der Sprachen unterrichtete: In der ersten Lektion des Tages neigte er dazu, am Lehrerpult einzunicken. So still war die Klasse dann den ganzen Tag nicht mehr, wie in diesen entspannten Minuten - bis sich unser Kichern und Lachen entlud und ihn wieder weckte. Und auch sonst war er das Gegenteil von Meister Lämpel: gedrungener Gestalt, gemütlich, warmherzig, unsportlich, lachte gerne und viel. Von ihm habe ich gelernt, dass intellektuelle Leistung längst nicht alles ist.
Mit Kantonsschule und Uni stieg die Zahl der Lehrer stark, und an ihnen konnte ich beobachten, dass Ecken und Kanten bei sonst integren Persönlichkeiten ihre Beliebtheit nicht schmälerten, manchmal im Gegenteil. An die Zielwürfe meines Englischlehrers, mit Kreidestücken quer durchs Schulzimmer in den Papierkorb, erinnere ich mich gut (böse Zungen behaupteten, er übe heimlich daheim). Oder an das Hobby unseres Mathelehrers, mithilfe eines Koordinatensystems dreidimensionales Schach zu spielen - etwas skurril, aber bewundernswert und auf eine eigentümliche Art sympathisch.

Am Lehrspital ging es weiter mit der Prägung: Blitzgescheite, manchmal arrogante Professoren, warmherzige Hausärzte, zynische Assistenzärzte (eigentlich zu jung, um zynisch sein zu dürfen), bis in die Knochen tüchtige Stationsschwestern, und immer wieder: der leidende, bedürftige Patient, eigentlicher Auftraggeber für uns Ärzte. Und nicht zu vergessen die Mitstudenten, Kollegen, Familie - die Beschreibung ihres Einflusses würde weitere Seiten füllen.

Liebe Leser, Sie sehen schon, worauf ich hinaus will: Wir denken vielleicht, wir seien frei und selbstbestimmt in unserem Handeln; dabei sind wir bis ins Mark geformt durch «die Anderen», praktisch ein Produkt unserer Erfahrungen mit unseren Mitmenschen, «Kinder unserer Zeit». Da dies ja nur eine Kaffetisch-Ecke ist, verzichte ich auf die deterministisch-philosophische Belehrung dazu. Ausserdem ist heute ein so schöner Sommertag draussen ...

Korrespondenz:

Dr. med. Stefan Neuner-Jehle, MPH

Schmidgasse 8

6300 Zug

sneuner[at]bluewin.ch 